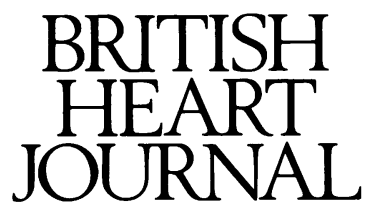

\title{
Viable myocardium and reinjection of thallium
}

Symptoms and prognosis in patients with coronary artery disease are related to the presence and extent of abnormal myocardial perfusion. The most successful methods of assessing perfusion directly use radioactive tracers such as thallium-201, cationic complexes of technetium-99m, and positron emitters such as rubidium- 82 and ${ }^{13} \mathrm{~N}$-ammonia. All of these radiopharmaceuticals rely on the principle that the initial tissue distribution of a tracer that is efficiently extracted from the blood reflects delivery of tracer and hence perfusion. ${ }^{1}$ The use of thallium has matured since its first description 17 years ago $^{2}$ and it now routinely provides diagnostic ${ }^{3}$ and prognostic information. ${ }^{4}$ It is superior to other non-invasive tests for the detection, ${ }^{5}$ localisation, ${ }^{6}$ and grading of coronary artery disease, ${ }^{7}$ and its ability to assess the extent of myocardial jeopardy makes it a predictor of future cardiac events ${ }^{8}$ at least equal in power to coronary arteriography. ${ }^{79-11}$ The functional information provided by thallium complements the anatomical information provided by arteriography, and the distinction between the two means that a complete assessment of the patient with coronary disease often requires both types of information.

Early studies used two separate injections of thallium to compare exercise and resting perfusion, but this was abandoned when it was discovered that images acquired several hours after a stress injection were similar to those that would have been obtained had the thallium been injected at rest. ${ }^{1213}$ Such redistribution is the result of the equilibration between intracellular and extracellular thallium and it allows the reversibly ischaemic myocardium to make good the reduced delivery during stress by extracting thallium from the small amount remaining in the blood pool once relatively homogeneous resting perfusion is restored. Thus conventional interpretation of stress and redistribution thallium images equates a reversible defect with myocardium that is normally perfused at rest but ischaemic during stress, a severe and fixed defect with the absence of viable myocardium, and a mild but fixed defect with a mixture of scar and viable myocardium.

This all seemed satisfactory until the introduction of positron emission tomography and tracers such as ${ }^{18} \mathrm{~F}$ fluorodeoxyglucose (FDG), which allowed the assessment of myocardial metabolism and showed that conventional stress and redistribution thallium imaging underestimated the presence of metabolically active myocardium. In 1986 Tillisch and colleagues showed that myocardium with impaired function, reduced perfusion, but increased glucose metabolism was capable of recovering mechanical function after restoration of blood flow. ${ }^{14}$ Such areas are now commonly referred to as "hibernating". 15 The next year the same group compared conventional stress and redistibution thallium imaging with FDG imaging and showed that glucose metabolism (and hence presumably viable myocardium) was present in $58 \%$ of segments with a fixed thallium defect. ${ }^{16}$ Other studies that had cast doubt on the equation of a fixed defect with irreversible myocardial injury included pathological studies ${ }^{17}$ and the fact that uptake could improve in fixed defects after angioplasty ${ }^{18}$ and bypass grafting. ${ }^{19}$ Thus the reliance on a perfusion marker alone for the assessment of myocardial viability risked underestimation of the extent of salvageable tissue.

Used appropriately, however, thallium is more than a perfusion marker because the completed redistribution pattern provides an image of viable myocardium unmodified by differences of perfusion between territories (figure). In this respect thallium differs from most other perfusion tracers which either do not redistribute $\left({ }^{99 \mathrm{~m}} \mathrm{Tc}-\right.$ methoxy-isobutyl-isonitrile $)^{20}$ or which have such short half lives that imaging of a redistribution pattern is impossible $\left({ }^{87} \mathrm{Rb}\right)$. The distinction between early (perfusion) and late (viability) thallium images has been known for many years ${ }^{21-23}$ although only more recently have its full implications for the detection of hibernating myocardium been appreciated. One problem is that redistribution can be a slow process and conventional four hour images may not provide reliable information. In one study that compared 4 and 24 hour redistribution imaging, the later images showed reversibility in $64 \%$ of defects that were irreversible at 4 hours. ${ }^{24}$ Ninety five percent of these reversible segments showed improved thallium uptake after revascularisation compared with $37 \%$ of the fixed defects. The rate of redistribution seems to be related to the rate of perfusion because myocardium that is subtended by occluded or tightly stenosed arteries has particularly slow redistribution. ${ }^{25} 26$

Unfortunately, late imaging gives low count rates and poor images and an obvious alternative is to give a second injection of thallium at rest. ${ }^{27} 28$ Dilsizian and colleagues acquired conventional redistribution images three to four hours after stress injection of $74 \mathrm{MBq}$ of thallium, and they then gave a further $37 \mathrm{MBq}$ at rest. Approximately half of the segments with fixed defects at three hours had improved uptake after reinjection. ${ }^{27}$ In 20 of their 100 patients who subsequently underwent coronary angioplasty $13(87 \%)$ of 15 regions identified as viable by reinjection had normal uptake and improved wall motion after the intervention, and none of the eight regions with fixed defects on reinjection imaging had any improvement in uptake or wall motion. Images acquired in this way are an amalgamation of the redistributed initial injection and the pattern of the resting injection. The resting injection will initially distribute itself according to resting perfusion and so a territory with stress-induced ischaemia and slow redistribution will appear to improve because of equal delivery of thallium to the normal territory and to the affected territory at rest. In theory, a territory with viable 


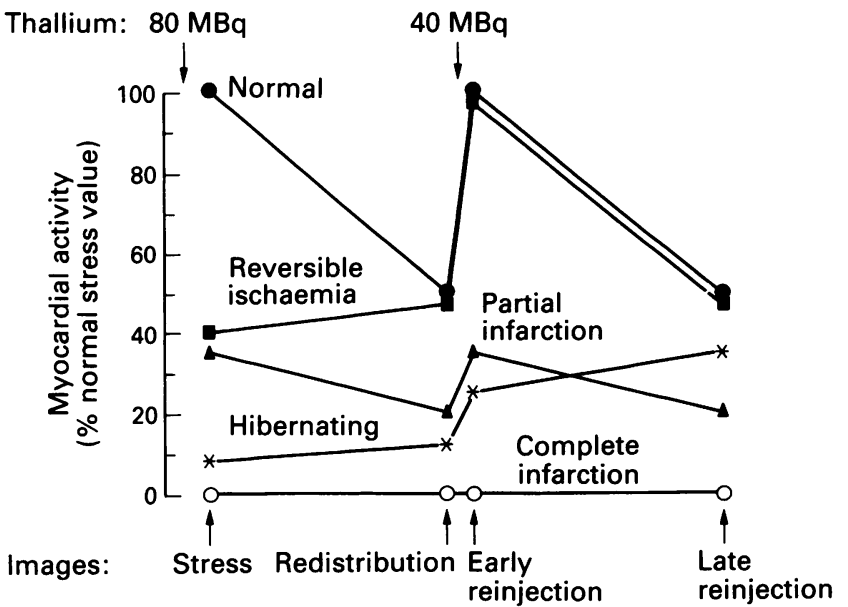

Myocardial thallium activity in four different types of myocardial abnormality compared with normal uptake immediately after stress, after redistribution, immediately after reinjection of thallium at rest, and after a further period of redistribution. Uptake is expressed as a percentage of the normal uptake immediately after stress, although the appearance of a defect depends upon the ratio between normal and abnormal myocardium at any one time. Reversibly ischaemic myocardium shows total redistribution even before reinjection. Partial thickness and complete infarction show a fixed defect which is either partial or complete. Viable myocardium with poor resting flow (potentially hibernating) shows a slow early increase in uptake, an increase after reinjection, and a further increase with later redistribution. Hence the redistribution may not be visually apparent until after reinjection.

myocardium but reduced resting perfusion will still show a defect immediately after resting injection, but further redistribution will equalise the uptake in viable myocytes irrespective of perfusion. This suggests that the reinjection images should not be acquired immediately after reinjection but after another period of redistribution..$^{29} 30$ In practice, immediate imaging may be sufficient. Dilsizian and colleagues studied a further 50 patients with chronic stable angina and showed that 23 of 25 segments with improved uptake immediately after reinjection showed no further improvement 24 hours later and that 29 of 30 segments with fixed defects immediately after reinjection remained fixed 24 hours later. ${ }^{31}$

Two practical implications of reinjection should be considered. First, uncertainty about the need for an additional dose of thallium and the extra imaging time required can play havoc with a busy clinical schedule, not to mention the departmental budget. Second, $40 \mathrm{MBq}$ of thallium after an initial injection of $80 \mathrm{MBq}$ will exceed the maximum dose recommended in the United Kingdom by the Administration of Radioactive Substances Advisory Committee (ARSAC), although not that commonly given in other countries. Specific approval should therefore be sought for such a protocol.

Given what we now know, can positron emission tomography still justify its main clinical indication, which is for the assessment of myocardial viability using FDG? When Bonow and colleagues compared thallium reinjection with DGG images they found FDG uptake in $91 \%$, $84 \%$, and $51 \%$ of segments which had mild, moderate and severe fixed thallium defects after four hour redistribution imaging. ${ }^{32}$ Thus only for the severe fixed defects was conventional thallium imaging inadequate. Reinjection of thallium showed viable myocardium in $51 \%$ of the severe fixed defects and there was $88 \%$ concordance between FDG imaging and thallium reinjection. Tamaki and colleagues have also compared the two and have shown that $65 \%$ of segments with viable myocardium predicted by thallium had improved function after bypass grafting but only $25 \%$ of segments judged to be nonviable by thallium had improved function. ${ }^{33}$ Thus there is broad agreement between thallium reinjection and FDG imaging, and whether the superior imaging characteristics of positron emitters will make any difference in clinical practice remains to be seen.

And what of alternative methods of detecting hibernating myocardium that do not rely on radioactive tracers? Bear in mind that the different metabolic and mechanical functions of the cardiac myocyte may not be damaged and recover in parallel and that in practical terms the most important aspect of viability is recovery of mechanical function after intervention. The response of myocardial motion and thickening to inotropic challenge may therefore be important. Echocardiography has shown that the ability of a region to improve systolic wall thickening in response to dobutamine stress predicts an improvement of abnormal resting function after revascularisation. ${ }^{34}$ However, because myocardial thickening can deteriorate with dobutamine induced ischaemia ${ }^{35}$ the full story is unlikely to be told without a knowledge of perfusion as well as of contractile function.

What therefore can we conclude about the routine use of thallium in patients with coronary artery disease? Certainly, conventional imaging with stress and 2-4 hour redistribution imaging should continue unchanged for the detection and assessment of coronary artery disease. Such a policy will answer most questions posed by myocardial perfusion imaging in patients with stable coronary artery disease. Even if redistribution is incomplete at four hours, later imaging or reinjection will not provide additional information. If, however, it is important to know whether there is viable myocardium within an area of absent uptake, than a further injection will answer the question with reasonable confidence. Such a question might arise if the scan shows no other area of reversible ischaemia in a patient with previous infarction and recurrent angina, or in a patient with ischaemic heart failure in whom revascularisation is being considered to improve ventricular function as much as to relieve angina. The ability to detect hibernating myocardium in this way widens the indications for thallium imaging and highlights the importance of the assessment of myocardial perfusion and viability in complementing the knowledge of coronary anatomy provided by invasive investigation.

SR UNDERWOOD DJ PENNELL

Royal Brompton National Heart and Lung Hospital,

Sydney Street

London SW3 $6 \mathrm{NP}$

1 Sapirstein LA, Moses JE. Cerebral and cephalic blood flow in man: basic consideration of the indicator fraction technique. Dynam Clin Stud Radioisotopes 1964;3:135.

2 Strauss HW, Harrison K, Langan JK, et al. Thallium-201 for myocardia imaging: relation of thallium-201 to myocardial perfusion. Circulation imaging: relation

3 Kotler TS, Diamond GA. Exercise thallium-201 scintigraphy in the diagnosis and prognosis of coronary artery disease. Ann Intern Med 1990 diagnosis and

4 Brown KA. Prognostic value of thallium-201 myocardial perfusion imaging. A diagnostic tool comes of age. Circulation 1991;83:363-81.

5 Gibson RS, Beller GA. Should exercise electrocardiography be replaced by radionuclide methods? In: Rahimtoola SH, Brest AN, eds. Controversies in coronary artery disease. Philadelphia: Davis, 1982:1-33.

6 DePasquale EE, Nody AC, DePuey EG, et al. Quantitative rotational thallium-201 tomography for identifying and localising coronary artery disease. Circulation 1988;77:316-27.

7 Gibson RS, Watson DD, Craddock GB, et al. Prediction of cardiac event after uncomplicated myocardial infarction: a prospective study comparing predischarge exercise thallium-201 scintigraphy and coronary angiography. Circulation 1983;68:321-36.

8 Ladenheim ML, Pollock BH, Rozanski, et al. Extent and severity of myocardial hypoperfusion as predictors of prognosis in patients with suspected coronary artery disease. J Am Coll Cardiol 1986;7:464-71.

9 Brown KA, Boucher CA, Okada RD, et al. Prognostic value of exercise thallium-201 imaging in patients presenting for evaluation of chest pain. $J$ Am Coll Cardiol 1983;1:994-1001

10 Kaul S, Finkelstein DM, Homma S, Leavitt M, Okada RD, Boucher CA. 
Superiority of quantitative exercise thallium-201 variables in determining long term prognosis in ambulatory patients with chest pain: a comparison with cardiac catheterisation. J Am Coll Cardiol 1988;12:25-34.

11 Kaul S, Lilly DR, Gascho JA, et al. Prognostic utility of the exercise thallium-201 test in ambulatory patients with chest pain: comparison with cardiac catheterisation. Circulation 1988;77:745-58.

12 Pohost GM, Zir LM, Moore RH, McKusick KA, Guiney TE, Beller GA Differentiation of transiently ischaemic from infarcted myocardium by Differentiation of transiently ischaemic from infarcted myocardium by
serial imaging after a single dose of thallium-201. Circulation 1977;55: serial imagin.

13 Blood DK, McCarthy DM, Sciacca RR, Cannon PJ. Comparison of single dose and double dose thallium-201 myocardial perfusion scintigraphy for the detection of coronary artery disease and prior myocardial infarction. Circulation 1981;58:777-88.

14 Tillisch J, Brunken R, Marshall R, et al. Reversibility of cardiac wall motion abnormalities predicted by positron tomography. $N$ Engl J Med 1986; 314:884-8.

15 Braunwald E, Rutherford JD. Reversible ischemic left ventricular dysfunction: evidence for the "hibernating myocardium". J Am Coll Cardiol 1986;8:1467-70.

16 Brunken R, Schwaiger M, McKay MG, Phelps ME, Tillisch J, Schelbert HR. Positron emission tomography detects tissue metabolic activity in myocardial segments with persistent thallium perfusion defects. $\mathrm{J} \mathrm{Am} \mathrm{Coll}$ Cardiol 1987;10:557-67.

17 Bulkley BH, Silverman K, Weisfeldt ML, Burow R, Pond M, Becker LC. Pathological basis of thallium-201 scintigraphic defects in patients with fatal myocardial injury. Circulation 1979;60:785-92.

18 Liu P, Kiess MC, Okada RD, et al. The persistent defect on exercise thallium imaging and its fate after revascularisation: does it represent scar or imaging and its fate after revascularisation:

19 Gibson RS, Watson DD, Taylor GJ, et al. Prospective assessment of regional myocardial perfusion before and after coronary revascularisation surgery by quantitative thallium-201 scintigraphy. J Am Coll Cardiol 1983;1: 804-15.

20 Cuocolo A, Pace L, Ricciardelli B, Chiariello M, Trimarco B, Salvatore M. Identification of viable myocardium in patients with chronic coronary artery disease: comparison of thallium-201 scintigraphy with reinjection and technetium-99m-methoxyisobutyl isonitrile. J Nucl Med 1992;33: 505-11.

21 Gewirtz H, Beller GA, Strauss HW, et al. Transient defects of resting thallium scans in patients with coronary artery disease. Circulation 1979;59:707-13.

22 Berger BC, Watson DD, Burwell LR. Redistribution of thallium at rest in patients with stable and unstable angina and the effect of coronary artery bypass surgery. Circulation 1979;60:1114-25.

23 Ritchie JL, Albro PC, Caldwell JH, Trobaugh GB, Hamilton GW.
Thallium-201 myocardial imaging: a comparison of the redistribution and rest images. J Nucl Med 1979;20:477-83.

$24 \mathrm{Kiat} \mathrm{H}$, Berman DS, Maddahi J, et al. Late reversibility of tomographic myocardial thallium-201 defects: an accurate marker of myocardial viability. J Am Coll Cardiol 1988;12:1456-63.

25 Gutman J, Berman DS, Freeman M, et al. Time to complete redistribution of thallium-201 in exercise myocardial scintigraphy: relationship to the degree of coronary stenosis. Am Heart J 1983;106:989-95.

26 Tamaki N, Ohtani H, Yonekura Y, et al. Significance of fill-in after thallium 201 reinjection following delayed imaging: comparison with regional wall 201 reinjection following delayed imaging: comparison with regiona
motion and angiographic findings. J Nucl Med 1990;31:1617-23.

27 Dilsizian V, Rocco TP, Freedman NMT, Leon MB, Bonow RO. Enhanced detection of ischaemic but viable myocardium by the reinjection of thallium after stress-redistribution imaging. $N$ Engl $J$ Med 1990;323 thallium

28 Ohtani H, Tamaki N, Yonekura Y, Mohiuddin IH, Hirata K, Ban T, Konishi J. Value of thallium-201 reinjection after delayed SPECT imaging for predicting reversible ischemia after coronary artery bypass grafting. Am J Cardiol 1990;66:394-9.

29 Rocco TP, Dilsizian V, McKusick KA, Fischman AJ, Boucher CA, Straus $\mathrm{HW}$. Comparison of thallium redistribution with rest reinjection imaging for the detection of viable myocardium. Am J Cardiol 1990;66:158-63.

30 Mori T, Minamiji K, Kurogane H, Ogawa K, Yoshida Y. Rest-injected thallium-201 imaging for assessing viability of severe asynergic regions. J Nucl Med 1991;32:1718-24.

31 Dilsizian V, Smeltzer WR, Freedman NMT, Dextras R, Bonow RO. Thallium reinjection after stress-redistribution imaging: does 24-hour delayed imaging after reinjection enhance detection of viable myocardium? Circulation 1991;83:1247-55.

32 Bonow RO, Dilsizian V, Cuocolo A, Bacharach SL. Identification of viable myocardium in patients with chronic coronary artery disease and left ventricular dysfunction. Comparison of thallium scintigraphy with reventricular dysfunction. Comparison of thallium scintigraphy with reinjection and $1991 ; 83: 26-37$.

33 Tamaki N, Ohtani $\mathrm{H}$, Yamashita $\mathrm{K}$, et al. Metabolic activity in the areas of new fill-in after thallium-201 reinjection: comparison with positron new fill-in after thallium-201 reinjection: comparison with positron emission

34 Pierard LA, De Landsheere CM, Berthe C, Rigo P, Kulbertus HE. Identification of viable myocardium by echocardiography during dobutamine infusion in patients with myocardial infarction after thrombolytic therapy: comparison with positron emission tomography. $J A m$ Coll Cardiol 1990;15:1021-31.

35 Pennell DJ, Underwood SR, Manzara CC, et al. Magnetic resonance imaging during dobutamine stress in patients with coronary artery disease. Am J Cardiol 1992;70:34-40. 